\title{
PERLINDUNGAN PATEN PADA APLIKASI SMARTPHONE
}

\author{
Putri Indah Sari \\ 155100093, 785567921 \\ Fakultas Komputer \\ Putriindahsari.student@umitra.ac.id
}

\begin{abstract}
Pada saat yang sama waktu, komputer produk perangkat lunak yang mungkin yang paling berat dilindungi dari semua bentuk berbasis pengetahuan produk. Masalah kedua adalah dimana kode sumber dari perangkat lunak ini juga dilindungi, ini dapat membuat lebih sulit untuk mengadaptasi produk untuk kebutuhan lokal. Hal ini juga mungkin membatasi persaingan dalam pengembangan aplikasi antar-operasi,melalui tindak pada inovasi oleh reverse engineering. Dalam TRIPS, negara-negara berkembang diperbolehkan fleksibilitas untuk memungkinkan reverse engineering perangkat lunak,sehingga masalah ini dapat dihindari jika nasional undang-undang hak cipta yang dirancang tepat. Sebagai ukuran lain praktis, lebih luas penggunaan berbagai open source software produk, di mana kode sumber tersedia tidak seperti perangkat lunak berpemilik,dapat diterima atau beberapa di industri berpendapat bahwa dengan penegakan hak cipta lebih kuat,sumber tertutup karena pengembang proprietary mungkin lebih bersedia untuk membuat kode sumber tersedia untuk pengembang perangkat lunak dalam mengembangkan negara. Hal ini jelas di luar mandat kami untuk merekomendasikan jenis kebijakan pengembangan negara harus diikuti untuk pengadaan perangkat lunak komputer.

pengembang aplikasi harus mengetahui bagaimana peraturan sebuah karya cipta bisa dilindungi. Hal ini cukup penting menurut saya, karena di era internet ini pembajakan bisa saja menimpa kita. Mungkin yang lebih parah kalau sudah berurusan dengan hukum karena kita sembarangan menggunakan karya milik orang lain tanpa izin. Hal ini berlaku pula untuk sebaliknya, tentu tidak enak apabila pelanggaran Hak Cipta malah menimpa pengembang aplikasi. Misalnya: aplikasi yang telah dibuat dengan menghabiskan banyak energi malah beberapa hari kemudian sudah terbit bajakannya dengan komponen aplikasi yang sama persis, bahkan mungkin jumlah download-nya lebih besar dari aplikasi milik pengembang aplikasi aslinya.
\end{abstract}

Kata Kunci : Perlindungan Aplikasi,Hak Paten Produk. 


\section{A. INTRODUCTION}

Ada kesenjangan digital antara negara maju dan dunia berkembang. Dalam ekonomi global berbasis pengetahuan, komputer teknologi merupakan persyaratan penting untuk mengakses dan menggunakan informasi, mempercepat transfer teknologi dan mendorong pertumbuhan produktivitas. Pada saat yang sama waktu, komputer produk perangkat lunak yang mungkin yang paling berat dilindungi dari semua bentuk berbasis pengetahuan produk. Masalah kedua adalah dimana kode sumber dari perangkat lunak ini juga dilindungi, ini dapat membuat lebih sulit untuk mengadaptasi produk untuk kebutuhan lokal. Hal ini juga mungkin membatasi persaingan dalam pengembangan aplikasi antar-operasi,melalui tindak pada inovasi oleh reverse engineering. Dalam TRIPS, negara-negara berkembang

diperbolehkan fleksibilitas untuk memungkinkan reverse engineering perangkat lunak,sehingga masalah ini dapat dihindari jika nasional undangundang hak cipta yang dirancang tepat. Sebagai ukuran lain praktis, lebih luas penggunaan berbagai open source software produk, di mana kode sumber tersedia tidak seperti perangkat lunak berpemilik,dapat diterima atau beberapa di industri berpendapat bahwa dengan penegakan hak cipta lebih kuat,sumber tertutup karena pengembang proprietary mungkin lebih bersedia untuk membuat kode sumber tersedia untuk pengembang perangkat lunak dalam mengembangkan negara. Hal ini jelas di luar mandat kami untuk merekomendasikan jenis kebijakan pengembangan negara harus diikuti untuk pengadaan perangkat lunak komputer. Sebagai contoh, sementara rendah biaya atau perangkat lunak open source mungkin tawaran apriori biaya dan keuntungan lainnya selama perangkat lunak berpemilik, banyak faktor selain biaya lisensi perangkat lunak mempengaruhi total biaya dari Sistem TI seperti menyesuaikan sistem dengan kebutuhan pengguna, serta pelayanan, dan memelihara sistem. Yang mengatakan, mengingat kebutuhan yang cukup negara berkembang untuk teknologi informasi dan komunikasi dan keterbatasan dana 
yang tersedia, tampaknya masuk akal bahwa pemerintah dan donor tentu harus mempertimbangkan untuk mendukung program-program untuk meningkatkan kesadaran tentang opsiopsi biaya rendah, termasuk perangkat lunak open-source, di negara-negara berkembang. Pada saat ini sebagian besar negara memiliki perangkat lunak dan program komputer yang dilindungi hak cipta. Kekayaan intelektual adalah kekayaan yang timbul dari kemampuan intelektual manusia yang dapat berupa karya di bidang teknologi, ilmu pengetahuan, seni dan sastra. Karya ini dihasilkan atas kemampuan intelektual melalui pemikiran, daya cipta dan rasa yang memerlukan curahan tenaga, waktu dan biaya untuk memperoleh "produk" baru dengan landasan kegiatan penelitian atau yang sejenis.

\section{HAK PATEN}

Hak eksklusif yang diberikan oleh Negara atas hasil invensinya di bidang teknologi, yang untuk selama waktu tertentu melaksanakan sendiri untuk ivensinya tersebut atau memberikan persetujuan kepada pihak lain untuk melaksanakannya. Dasar hukum Hak Paten : Undang-Undang No 14 tahun 2001 tentang hak paten.

\section{-Jangka Waktu Paten}

Bardasarkan Pasal 8 Undang-Undang Nomor 14 Tahun 2001 tentang Paten, paten diberikan untuk jangka waktu selama 20 tahun, terhitung sejak tanggal penerimaan dan jangka waktu itu tidak dapat diperpanjang, sedangkan untuk paten sederhana diberikan jangka waktu 10 tahun, terhitung sejak tanggal penerimaan dan jangka waktu tidak dapat diperpanjang.

-Permohonan Paten

Paten diberikan atas dasar permohonan. Setiap permohonan hanya dapat diajukan untuk satu invensi atau beberapa invensi yang merupakan satu kesatuan invensi. Permohonan paten diajukan dengan membayar biaya kepada Direktorat Jendral Hak Paten Departemen Kehakiman dan HAM untuk memperoleh sertifikat paten sebagai bukti hak atas paten. Paten mulai 
berlaku pada tanggal diberikan sertifikat paten dan berlaku sejak tanggal perimaan.

-Pengalihan Paten

Berdasarkan Pasal 66 Undang-Undang Nomor 14 Tahun 2001 tentang Paten, paten dapat beralih atau dialihkan baik seluruh maupun sebagian karena pewarisan, hibah, wasiat, perjajian tertulis, atau sebab lain yang dibenarkan oleh peraturan perundangundangan. Segala bentuk pengalihan paten wajib dicatat dan diumumkan di Direktorat Jendral, pengalihan paten yang tidak sesuai dengan di atas tidak sah dan batal demi hukum.

\section{B. CONTENT}

Studi Kasus Perlindungan Aplikasi Pada Smartphone Iphone X

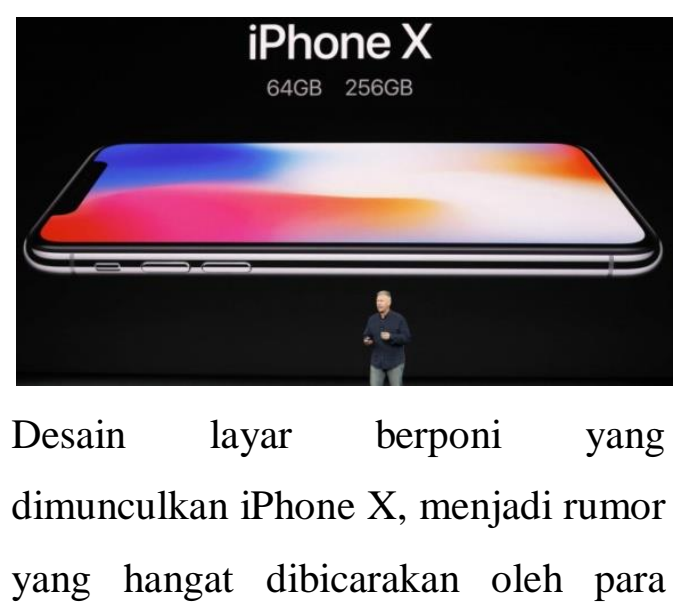

penggemar gadget. Beberapa media China, mendapatkan bocoran adanya vendor smartphone asal negara itu yang memiliki paten desain 'poni' atau notch lebih dulu ketimbang Apple. Media online di China, menyebarkan foto smartphone Oppo yang desainnya mirip sekali dengan iPhone X. Diduga, smartphone itu adalah Oppo R15. Selain berponi, layarnya juga penuh dengan bezel yang hampir tipis.

Jika foto yang beredar itu benar adanya, Oppo akan menjadi vendor China pertama yang menghadirkan smartphone dengan notch dan layar penuh. Sebelumnya, baru vendor Taiwan, Asus yang mengeluarkan desain seperti iPhone $\mathrm{X}$ itu. Media online di China, menuliskan paten desain notch dan full-display itu sejatinya sudah dipaparkan dengan gamblang di situs resmi kantor Hak Paten China. Oppo dikabarkan telah mendaftarkan paten itu di kantor tersebut sejak 9 januari 2017. 
Hak Paten Layar Sentuh (Touch Screen)

Touch screen merupakan sebuah perangkat input komputer yang bekerja dengan adanya sentuhan tampilan layar menggunakan jari atau pena digital. Hampir semua perangkat teknologi saat ini lebih banyak menggunakan teknologi touch screen seperti di smartphone maupun laptop. Pemegang paten ini adalah seorang penemu asal Amerika yaitu George Samuel Hurst, yang menerima paten ini pada tanggal 7 Oktober 1975 dengan versi pertamanya yang diproduksi pada tahun 1982.

Sebagai pembuat suatu karya digital, pengembang aplikasi harus mengetahui bagaimana peraturan sebuah karya cipta bisa dilindungi. Hal ini cukup penting menurut saya, karena di era internet ini pembajakan bisa saja menimpa kita. Mungkin yang lebih parah kalau sudah berurusan dengan hukum karena kita sembarangan menggunakan karya milik orang lain tanpa izin.
Hal ini berlaku pula untuk sebaliknya, tentu tidak enak apabila pelanggaran Hak Cipta malah menimpa pengembang aplikasi. Misalnya: aplikasi yang telah dibuat dengan menghabiskan banyak energi malah beberapa hari kemudian sudah terbit bajakannya dengan komponen aplikasi yang sama persis, bahkan mungkin jumlah download-nya lebih besar dari aplikasi milik pengembang aplikasi aslinya.

\section{Manfaatnya Bagi Pengembang Aplikasi}

Dalam sebuah aplikasi Smartphone atau disebuah game, biasanya terdiri dari banyak komponen di dalamnya. Dengan adanya Hak Cipta ini, pengembang aplikasi dapat melindungi komponen yang dimiliki, antara lain: gambar / icon, karakter, musik, prototype, dan tentunya aplikasi itu sendiri. Sehingga pengembang aplikasi bisa melawan bila kasus pembajakan menimpa aplikasinya. Sering mengikuti hackathon, lomba submit aplikasi atau sejenisnya? Saran dari Ari Juliano saat saya berbincang singkat dengan beliau adalah 
perhatikan Term \& Condition yang diberikan. Biasanya terbagi atas 2 bagian, yaitu:

- Aplikasi yang sudah didaftarkan menjadi hak milik penyelenggara, atau

- Bila tidak dideklarasi di bagian Term \& Condition biasanya aplikasi masih menjadi milik penuh pengembang aplikasi. Bila ragu-ragu, segera tanyakan ke pihak penyelenggara.

Semoga dengan meleknya pengembang aplikasi terhadap Hak Cipta, tidak akan ada pengembang aplikasi yang harus bersengketa atau berurusan dengan hukum saat mengembangkan suatu aplikasi. Harapan juga dilayangkan agar saling menghargai diantara para pengembang aplikasi. Sangat tidak enak rasanya bila karya kita disalahgunakan (apalagi dibajak) oleh pihak tertentu, apalagi kalau mengingat energi yang sudah dikeluarkan untuk mengembangkan suatu produk beserta komponen yang ada di dalamnya.
Istilah "paten" sering kita dengar banyak dipakai oleh masyarakat luas; dan bahkan tak jarang disalah-pahami sebagai padanan dari istilah "hak kekayaan intelektual" itu sendiri. Namun sesungguhnya, paten hanyalah salah-satu dari sekian banyak bentuk perlindungan HKI. Paten adalah perlindungan HKI bagi karya intelektual yang bersifat teknologi, atau dikenal juga dengan istilah invensi, dan mengandung

pemecahan/solusi teknis terhadap masalah yang terdapat pada teknologi yang telah ada sebelumnya. Sebagai contoh, paku kecil temuan Levi Strauss untuk dipasang di ujungujung saku celana jeans, misalnya, yang kemudian dianugerahi hak paten di Amerika Serikat tahun 1873, mengandung solusi teknis terhadap persoalan mudah lepas/sobeknya jahitan saku celana berbahan denim ketika itu, mengingat pemakaian luar ruangan dengan intensitas yang cukup tinggi.

Invensi paten dapat berupa produk ataupun proses. Contohnya pembakaran pada mesin kendaraan bermotor yang bertujuan untuk 
menghasilkan emisi gas buang yang lebih ramah lingkungan. Baik metode dan proses bagaimana pembakaran tersebut dilakukan, dan mesin yang menerapkan metode dan proses pembakaran itu, keduanya dapat dipatenkan masing-masing sebagai paten proses dan paten produk.

Orang yang menghasilkan suatu invensi, baik sendirian maupun beberapa orang bersama-sama, disebut dengan istilah inventor. Inventor inilah yang paling pertama berhak mendapatkan hak paten atas invensi yang dihasilkannya. Siapapun di luar inventor yang ingin memiliki hak paten atas invensi tersebut harus terlebih dahulu memperoleh pengalihan hak secara tertulis dari sang inventor.

Baik Inventor maupun pihak lain yang menerima pengalihan hak dari inventor merupakan Pemilik/Pemegang Hak

Paten (Patentee), yang memiliki hak eksklusif untuk melaksanakan invensi yang dipatenkan tersebut selama 20 tahun dihitung dari Tanggal Penerimaan. Setelah 20 tahun tersebut, invensi yang dimaksud akan menjadi milik umum (public domain) dan dapat dimanfaatkan oleh siapapun tanpa perlu meminta izin dari si pemegang paten.

\section{CONCLUSION}

Kesimpulan dari materi ini adalah pengembang aplikasi harus mengetahui bagaimana peraturan sebuah karya cipta bisa dilindungi. Hal ini cukup penting menurut saya, karena di era internet ini pembajakan bisa saja menimpa kita. Mungkin yang lebih parah kalau sudah berurusan dengan hukum karena kita sembarangan menggunakan karya milik orang lain tanpa izin.

Hal ini berlaku pula untuk sebaliknya, tentu tidak enak apabila pelanggaran Hak Cipta malah menimpa pengembang aplikasi. Misalnya: aplikasi yang telah dibuat dengan menghabiskan banyak energi malah beberapa hari kemudian sudah terbit bajakannya dengan komponen aplikasi yang sama persis, bahkan mungkin jumlah download-nya lebih besar dari aplikasi milik pengembang aplikasi aslinya. Paten adalah perlindungan 
HKI bagi karya intelektual yang bersifat teknologi, atau dikenal juga dengan

istilah invensi, dan mengandung

pemecahan/solusi teknis terhadap masalah yang terdapat pada teknologi yang telah ada sebelumnya. Invensi paten dapat berupa produk ataupun proses. Contohnya pembakaran pada mesin kendaraan bermotor yang bertujuan untuk menghasilkan emisi gas buang yang lebih ramah lingkungan. Baik metode dan proses bagaimana pembakaran tersebut dilakukan, dan mesin yang menerapkan metode dan proses pembakaran itu, keduanya dapat dipatenkan masing-masing sebagai paten proses dan paten produk.

\section{DISCUSSION}

Hasil diskusi dari materi ini adalah Persaingan antar bisnis maupun perdagangan yang kuat beriringan dengan perkembangan teknologi yang juga kian pesat. Begitu banyak penemuan-penemuan baru yang ada hingga saat ini juga mengisyaratkan bahwa kita telah memasuki era modern dimana segalanya dinilai serba praktis.

Untuk bisa bersaing dan mendapatkan tempat di pasar, para inventor atau penemu melakukan pendaftaran untuk mendapatkan hak paten atas temuannya. Hak paten ini juga sebagai perlindungan hukum dari invensi agar tidak terjadi klaim dari pihak lain. Pemaparan mengenai telepon dan perkembangannya sedikit menjelaskan mengenai hak paten sebagai salah satu ruang lingkup dari Kekayaan Intelektual, dimana hak paten pada telepon konvensional dimiliki Antonio Meucii sedangkan hak paten dari handphone yaitu dipegang oleh Martin Cooper. Sebagai pembuat suatu karya digital, pengembang aplikasi harus mengetahui bagaimana peraturan sebuah karya cipta bisa dilindungi. Hal 
ini cukup penting menurut saya, karena di era internet ini pembajakan bisa saja menimpa kita. Mungkin yang lebih parah kalau sudah berurusan dengan hukum karena kita sembarangan menggunakan karya milik orang lain tanpa izin.

Hal ini berlaku pula untuk sebaliknya, tentu tidak enak apabila pelanggaran Hak Cipta malah menimpa pengembang aplikasi. Misalnya: aplikasi yang telah dibuat dengan menghabiskan banyak energi malah beberapa hari kemudian sudah terbit bajakannya dengan komponen aplikasi yang sama persis, bahkan mungkin jumlah download-nya lebih besar dari aplikasi milik pengembang aplikasi aslinya.

Semoga dengan meleknya pengembang aplikasi terhadap Hak Cipta, tidak akan ada pengembang aplikasi yang harus bersengketa atau berurusan dengan hukum saat mengembangkan suatu aplikasi. Harapan juga dilayangkan agar saling menghargai diantara para pengembang aplikasi. 


\section{E. REFERENCE}

[1] O. M. Febriani and A. S. Putra, "Sistem Informasi Monitoring Inventori Barang Pada Balai Riset Standardisasi Industri Bandar Lampung," J. Inform., vol. 13, no. 1, pp. 90-98, 2014.

[2] A. S. Putra, "Paperplain: Execution Fundamental Create Application With Borland Delphi 7.0 University Of Mitra Indonesia," 2018.

[3] A. S. Putra, "2018 Artikel Struktur Data, Audit Dan Jaringan Komputer," 2018.

[4] A. S. Putra, "ALIAS MANAGER USED IN DATABASE DESKTOP STUDI CASE DB DEMOS."

[5] A. S. Putra, "COMPREHENSIVE SET OF PROFESSIONAL FOR DISTRIBUTE COMPUTING."

[6] A. S. Putra, "DATA ORIENTED RECOGNITION IN BORLAND DELPHI 7.0."

[7] A. S. Putra, "EMBARCADERO DELPHI XE 2 IN GPUPOWERED FIREMONKEY APPLICATION."

[8] A. S. Putra, "HAK ATAS KEKAYAAN INTELEKTUAL DALAM DUNIA TEKNOLOGY BERBASIS REVOLUSI INDUSTRI 4.0."

[9] A. S. Putra, "IMPLEMENTASI PERATURAN PERUNDANGAN UU. NO 31 TAHUN $2000 \quad$ TENTANG DESAIN INDUSTRI BERBASIS INFORMATION TECHNOLOGY."

[10] A. S. Putra,
"IMPLEMENTATION OF PARADOX DBASE."

[11]

A. S. Putra, "IMPLEMENTATION OF

TRADE SECRET CASE STUDY SAMSUNG MOBILE PHONE."

[12] A. S. Putra, "IMPLEMENTATION

PATENT FOR APPLICATION WEB BASED CASE STUDI WWW. PUBLIKLAMPUNG. COM."

[13] A. Putra "IMPLEMENTATION SYSTEM FIRST TO INVENT IN DIGITALLY INDUSTRY."

[14] A. S. Putra, "MANUAL REPORT \& INTEGRATED DEVELOPMENT

ENVIRONMENT BORLAND DELPHI 7.0."

[15] A. S. Putra, "PATENT AS RELEVAN SUPPORT RESEARCH."

[16] A. S. Putra, "PATENT FOR RESEARCH STUDY CASE OF APPLE. Inc."

[17] A. S. Putra, "PATENT PROTECTION FOR APPLICATION INVENT."

[18] A. S. Putra, "QUICK REPORT IN PROPERTY PROGRAMMING."

[19] A. S. Putra, "REVIEW CIRCUIT LAYOUT COMPONENT

REQUIREMENT ON ASUS NOTEBOOK."

[20] A. S. Putra, "REVIEW TRADEMARK PATENT FOR INDUSTRIAL TECHNOLOGY BASED 4.0."

[21] A. S. Putra, "TOOLBAR COMPONENT PALLETTE IN 
OBJECT

ORIENTED

PROGRAMMING."

[22] A. S. Putra, "WORKING DIRECTORY SET FOR PARADOX 7."

[23] A. S. Putra, "ZQUERY CONNECTION

IMPLEMENTED

PROGRAMMING

STUDI

CASE PT. BANK BCA Tbk."

[24] A. S. Putra, D. R. Aryanti, and I. Hartati, "Metode SAW (Simple Additive Weighting) sebagai Sistem Pendukung Keputusan Guru Berprestasi (Studi Kasus: SMK Global Surya)," in Prosiding Seminar Nasional Darmajaya, 2018, vol. 1, no. 1, pp. 85-97.

[25] A. S. Putra and O. M. Febriani, "Knowledge Management Online Application in PDAM Lampung Province," in Prosiding International conference on Information Technology and Business (ICITB), 2018, pp. 181-187.

[26] A. S. Putra, O. M. Febriani, and B. Bachry, "Implementasi Genetic Fuzzy System Untuk Mengidentifikasi Hasil Curian Kendaraan Bermotor Di Polda Lampung," SIMADA (Jurnal Sist. Inf. dan Manaj. Basis Data), vol. 1, no. 1, pp. 21-30, 2018.

[27] A. S. Putra, H. Sukri, and K. Zuhri, "Sistem Monitoring Realtime Jaringan Irigasi Desa (JIDES) Dengan Konsep Jaringan Sensor Nirkabel," IJEIS (Indonesian J. Electron. Instrum. Syst., vol. 8, no. 2, pp. 221-232.

[28] D. P. Sari, O. M. Febriani, and
A. S. Putra, "Perancangan Sistem Informasi SDM Berprestasi pada SD Global Surya," in Prosiding Seminar Nasional Darmajaya, 2018, vol. 1, no. 1, pp. 289-294. 